\title{
Mandibular premolar transposition: A rare case report
}

\author{
Sasidharan Sivakumar ${ }^{1,2}$, Julia Thenmozhi ${ }^{1}$ \\ From ${ }^{1}$ BDS, ${ }^{2}$ MDS, Department of Public Health Dentistry, Tn. Dr. M.G.R. Medical University, Chennai, Tamil Nadu, India
}

\begin{abstract}
Tooth transposition is one of the most difficult dental anomalies to treat in the dental clinic. The etiology of tooth transposition has been the subject of much controversy and is still not completely understood. Multifactorial genetic factors, an interchange in the position of the developing dental lamina of the involved teeth, and even trauma to the deciduous teeth in which dilacerations of the permanent incisor root was found have all been suggested as causes for transposition of teeth. The management of posterior tooth transposition is purely subjective until and unless the patient reported with some unstable occlusal patterns or functional insufficiency. This present case report with complete transposition of mandibular left second premolar erupted in the site of mandibular left first molar in a 42-year-old female patient is a rare case entity for clinical consideration.
\end{abstract}

Key words: Dental anomaly, Genetic, Mandibular premolar, Transposition

$\mathrm{T}$ ooth transposition, a tooth eruption disturbance disorder is defined as a positional change of two teeth within the same quadrant. Tooth transposition is a unique condition of an ectopic eruption. It is a rare developmental anomaly with an obscure origin. Transposition of teeth has been observed and reported since the early $19^{\text {th }}$ century. In 1849 , Harris, in his first edition of "A Dictionary of dental sciences, biography, bibliography, and medical terminology," described transposition as an aberration in the position of teeth [1]. Several theories such as a genetic origin, interchange of the position of the developing tooth buds, trauma, and lack of deciduous canine tooth root resorption, prolonged retention of primary teeth have been proposed to explain the phenomenon of tooth transposition. A genetic origin is, however, reported as the main etiologic factor [2].

The five types of tooth transposition observed in the upper jaw were classified by Peck and Peck according to the teeth involved [3] as (a) canine - first premolar (Mx.C.P1); (b) canine - lateral incisor (Mx.C.I2); (c) canine to the first molar position (Mx.C.M1); (d) lateral incisor - central incisor (Mx.I2.I1); and (e) canine to the central incisor position (Mx.C.I1).Tooth transposition is a hindrance to esthetic and functional aspects of dentition [3]. The purpose of this article is to report a case of complete transposition in which the mandibular left second premolar erupted in between the first and second molars which is a quite rare scenario in clinical practice. This is the first case reported in the literature with the complete transposition in the

\section{Access this article online}

Received - 15 August 2020

Initial Review - 23 September 2020

Accepted - 26 September 2020

DOI: 10.32677/IJCR.2020.v06.i10.004 mandibular posterior teeth region without any involvement of canine dentition.

\section{CASE REPORT}

A 42-year-old female patient reported with complaints of pain in the right maxillary first molar for the past 10 days. The patient had a non-contributory medical history and also this is the patient's first dental visit. Dental history reveals the congenital absence of the third molar.

Clinical examination reveals transposed teeth in the mandibular left posterior teeth region without any complaint about it and present with Angle's Class 1 molar relationship and Class 1 canine relationship with a convex profile, showing complete transposition of the mandibular left second premolar having been erupted in the place of the mandibular left first molar. Furthermore, all other quadrants do not define any transposition disorder in it with a completely normal anatomical position. The transposed premolar was rotated slightly (Fig. 1).

Intraoral periapical radiograph revealed that the apex of its root being more distal toward the second molar with a mild spacing seen between the first molar and the transposed premolar (Fig. 2). The treatment of transposed teeth varies, depending on the circumstances. This patient, as age got advanced without any noticeable functional and esthetic challenges, got adapted to it without any treatment and also denied the treatment option to rebuild the teeth with the prosthetic crown.

Correspondence to: Dr. Sasidharan Sivakumar, No: 5, $12^{\text {th }}$ Cross Street, Mahalakshmi Nagar, Guduvancheri - 603 202, Chennai, Tamil Nadu, India. E-mail: sdmhoralcare@gmail.com

(C) 2020 The Author(s). This open access article is distributed under a Creative Commons Attribution (CC-BY) 4.0 license. 


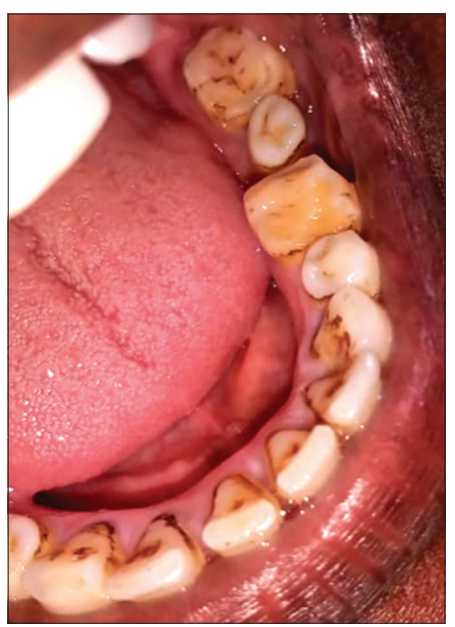

Figure 1: Clinical image of transposed premolar

\section{DISCUSSION}

The prevalence of transposition has been reported to be $0.4 \%$ but simultaneous occurrence in both dental arches and also the incidence in primary dentition were not reported [4]. Studies indicate upper canine - first premolar transposition was highly prevalent as compared to other types of transpositions, as well as, a higher predilection among the females and of its unilateral occurrence. Cases of transposition have been reported in either the maxilla or the mandible. The maxillary canine is most frequently involved [5]. In the mandible, transposition occurs even less frequently and is reported to involve the canine and lateral incisor only. It occurs in both males and females and interestingly it does not occur simultaneously in both the arches. When both the tooth crown and the root are transposed then it is called complete tooth transposition, or it is incomplete when the clinical crown is transposed, but the root apex remains in a relatively normal position.

The most prevalent variant of tooth transposition according to the Peck's classification is that the Mx.C.P1 transposition with an incidence of approximately $0.13 \%$ in the population, representing $71-89.2 \%$ of the cases, observed in the maxilla. Considering mandible, the most common transposition reported was between the canine and lateral incisor. Generally speaking, transpositions not involving the canine are extremely rare [6]. Similar frequencies in both genders have been described. The unilateral occurrence is more prevalent compared to bilateral prevalence (4:1), and the left side is the most commonly affected than the right side of the arch $[7,8]$. The bone density in the mandible is higher which might be a reason for the prohibition of the phenomenon of tooth transposition, and thus, it has a higher incidence in the maxilla [9]. The most common type of tooth transposition observed in the mandible takes place between the canines and lateral incisors, where the bone is more porous than in the posterior area [10]. However, this is a rare case scenario based on its type of occurrence in the mandibular posterior teeth region without the involvement of canines.

The treatment of transposed teeth varies, depending on the circumstances. Orthodontic treatment may be required to

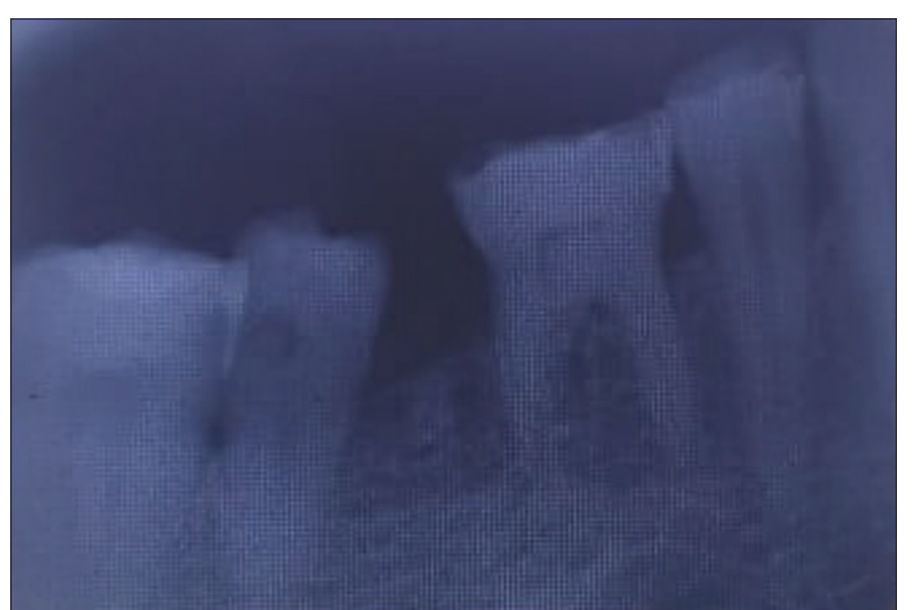

Figure 2: Radiographic image of transposed premolar

align the transposed teeth if the patient reported with some functional occlusal disharmony. Incisal or occlusal reduction and recontouring may be sufficient to treat some cases, whereas, others require endodontic therapy and crown restorations to establish good esthetics. No treatment may be best in some cases, if the patient is not concerned about the appearance and if, there exists a functionally stable occlusion. In our case, as the transposition was complete along with root apices, alignment of these transposed teeth into their ideal position may be damaging to the teeth or supporting structures, and also as the patient was aged, alignment is often an acceptable compromise [11]. As the patient has a satisfactory occlusion, no treatment has been progressed with regard to the transposed dentition.

\section{CONCLUSION}

Tooth transposition can compromise esthetic as well as the functional aspects of dentition, but not in all cases. For this reason, it is mandatory to know all the variables related to its etiology and prevalence to establish possible preventive measures. It can be successfully intervened provided that the diagnosis and orthodontic planning be meticulously carried out so that tooth movement is completely controlled. Furthermore, the biological limits should be considered in these cases, so as to prevent periodontal impairment and root resorption. Tooth transposition treatment includes a multidisciplinary approach based on the requirements embracing orthodontics, periodontology, and cosmetic dentistry was rendered necessary to achieve good esthetic results, function, as well as the stability.

\section{REFERENCES}

1. Harris CA. A Dictionary of Dental Sciences, Biography, Bibliography and Medical Terminology. $1^{\text {st }}$ ed. Philadelphia, PA: Lindsay and Blakiston; 1849. p. 725 .

2. Ely NJ, Sherriff M, Cobourne MT. Dental transposition as a disorder of genetic origin. Eur J Orthod 2006;28:145-51.

3. Mattos BS, Carvalho JC, Matusita M, Alves AP. Tooth transposition-a literature review and a clinical case. Braz J Oral Sci 2006;5:953-7.

4. Ruprecht A, Batniji S, El-Neweihi E. The incidence of transposition of teeth in dental patients. J Pedod 1985;9:244-9. 
5. Shapira Y, Kuftinec MM. Maxillary canine-lateral incisor transposition-orthodontic management. Am J Orthod Dentofacial Orthop 1989;95:439-44.

6. Hatzoudi M, Papadopoulos MA. Prevalence of tooth transposition in Greek population. Hell Orthod Rev 2006;9:11-22.

7. Papadopoulos MA, Chatzoudi M, Kaklamanos EG. Prevalence of tooth transposition. A meta-analysis. Angle Orthod 2010;80:275-85.

8. Shapira Y, Kuftinec MM. Maxillary tooth transpositions: Characteristic features and accompanying dental anomalies. Am J Orthod Dentofacial Orthop 2001;119:127-34.

9. Nagaveni NB, Radhika NB, Kumar A, Bajaj M, Poornima P. Tooth transposition: Report of three cases and literature review. Niger J Exp Clin Biosci 2015;3:52-6.
10. Thilander B, Jakobsson SO. Local factors in impaction of maxillary canines. Acta Odontol Scand 1968;26:145-68.

11. Shapira Y, Kuftinec MM. Tooth transpositions--a review of the literature and treatment considerations. Angle Orthod 1989;59:271-6.

Funding: None; Conflicts of Interest: None Stated.

How to cite this article: Sivakumar S, Thenmozhi J. Mandibular premolar transposition: A rare case report. Indian J Case Reports. 2020;6(10):557-559. 